ganic 'guest-host' complexes known to contain anions is vast ${ }^{7}$. Unlike the cation crown complexes just described, most of these anion complexes contain nonexchangeable ions entrapped within polyhedral cages. The $\mathrm{PMo}_{12} \mathrm{O}_{40}{ }^{3-}$ ion, for example, has been described ${ }^{8}$ as a clathrated $\mathrm{PO}_{4}^{3--}$ ion. A new type of anion complex was recently prepared, however, in which anions like $\mathrm{Cl}^{-}$ and $\mathrm{NO}_{3}{ }^{-}$are bonded to shallow basketlike inorganic frameworks 9 . These may turn out to be true guest-host as opposed to hostage-host complexes.

Department of Chemistry,
University of Nebraska, W. DAY
Lincoln,
Nebraska 68588, USA
WALTER G. KLEMPERER
Department of Chemistry,
University of Illinois,
Urbana,
Illinois 61801 , USA

Department of Chemistry,

Hanvard University,

Cambridge,

Massachusetts 02138, USA

Mrtchell RePlies - I omitted heteropolys from my article on anions as guests in inorganic hosts because of space limitations and because the heteropolys are so well known. Nevertheless, my reference to the paper by Day et al. ${ }^{10}$ provided a lead-in, although I ought to have added Michael Pope's excellent monograph ${ }^{7}$.

The particular interest of Müller's work, and my concern, was the encapsulation of guest anions which were weakly bound and entities chemically distinct from the host framework. Whether a particular anion is a guest, or part of the overall structure, arises with a number of heteropolys. For the phosphomolybdates and tungstates, $\left[\mathrm{PM}_{12} \mathrm{O}_{40}\right]^{3-}$, the question is whether the oxygens of the phosphate are part of the framework - that is, whether the phosphate anion is a distinct entity. Clark and Hall, who solved the structure ${ }^{11}$, do indeed refer to the phosphate as a guest species for $\mathbf{M}=$ Mo but not for $\mathbf{M}=\mathrm{W}$. With regard to 'anion complexes', Heinrich et al. ${ }^{9}$ did not use the term 'guest-host', referring to their compounds as aggregates.

1. Mitchell, P. C. H. Nature 348, 15-16 (1990).

2. Fischer, J., Ricard, L. \& Weiss, R. J. Am. Chem. Soc. $\mathbf{9 8}$ 3050-3052 (1976)

3. Alizadeh, M. H., Harmalker, S. P., Jeannin, Y., Martin-Frére, J. \& Pope M. T. J. Am. Chem. Soc. 107, 2662-2669 (1985). 4. Robert, F., Leyrie, M., Hervé, G. Tézé, A. \& Jeannin, Y. Inorg. Chem. 19, 1746-1752 (1980).

5. Content, R. \& Tézé, A. Inorg. Chem. 24, 4610-4614 (1985).

6. Keggin, J. F. Nature 131, 908-909 (1933)

7. Pope, M. T. Heropoly and Isopoly Oxometalates (Springer, Berlin, 1983).

8. Boeyens, J. C. A., McDougal, G. J. \& Smit, J. V. R. J. Solid State Chem. 18, 191-199 (1976)

9. Heinrich, D. D., Folting, K. Streib, W. E., Huffman, J. C. \& Christou, G. J. Chem. Soc., Chem. Commun. 1411-1413 1989).

10. Day, V. W., Klemperer, W. G. \& Yaghi, O. M. J. Am. Chem Soc. 111, 5959-5961 (1989).

11.Clark, C. J. \& Hall, D. Acta Cryst. B32, 1545-1547 (1976).
Let us agree about the questions to be asked. Which came first, the host or the guest (is the guest a template)? How far is the encapsulation of the anionic guest dependent on a structural match with the host cavity (molecular recognition)? Is the host stable without the guest? And finally, particularly important for applications, can we move the guest out of the host cavity (or is it really a 'hostage')? My article and this correspondence have provided a perspective on inor-

\section{High salinity in the North Sea}

SIR - The salinity of sea water in the northeast Atlantic has been documented since 1902; several large-scale fluctuations have been detected. During the mid 1970s the salinity declined to low levels not encountered since 1908 (ref. 1), increasing to more usual levels during the $1980 \mathrm{~s}$. Atlantic water flows into the northern North Sea between the Orkney and Shetland isles, and between Shetland and Norway, and a corresponding outflow from the North Sea occurs along with Norwegian coast. Changes in salinity in the nothern North Sea during the 1970 s paralleled those in the North Atlantic ${ }^{2}$, and were correlated with changes in fish stocks and plankton composition ${ }^{3,4}$. We now report the discovery in January 1990 of an inflow of water of exceptionally high salinity into the northern North Sea.

We conducted a survey in $56^{\circ} 30^{\prime} \mathrm{N}$

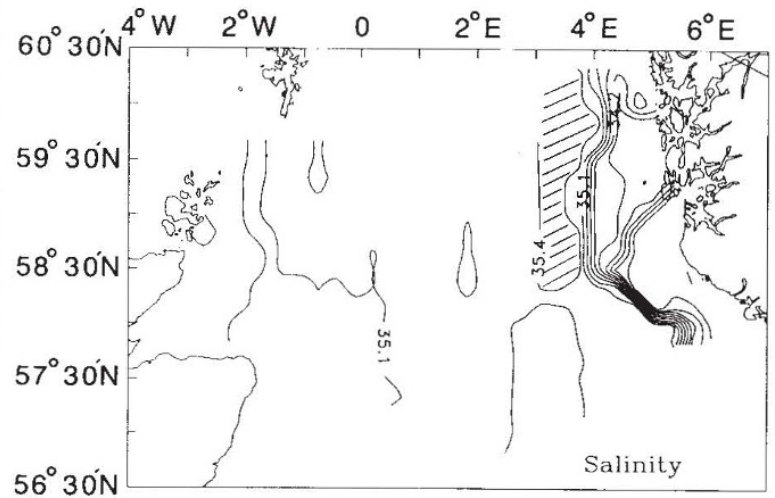

the northern North Sea from Distribution of salinity at 5-m depth in the northern North Sea the vessel British Enterprise in January 1990 drawn from data collected at 180-s intervals III. Salinity and temperature at throughout the survey. Shaded area, water of salinity greater a depth of $5 \mathrm{~m}$ were recorded than 35.40 . from sensors towed alongside the ship, and water currents measured with a multiple beam echo-sounding device (acoustic doppler current profiler). The highest recorded salinities (greater than 35.45, maximum value 35.471 ) were found in a strip approximately $20-\mathrm{km}$ wide parallel to the Norwegian coast, corresponding to the area of inflow from the Atlantic (see figure). The water currents in the high salinity region were southerly, whereas $10-20 \mathrm{~km}$ to the east in the lower salinity $(33.5-35.0)$ Norwegian coastal water, the flow was northerly.

The maximum salinity was higher than any value measured in the North Sea by the Marine Laboratory, Aberdeen, since records began in 1920 (previously recorded maximum: 35.390 in August 1968). Salinities greater than 35.40 have been recorded on a number of occasions during this period in the Atlantic between Shetland and the Faroe Isles and at the edge of the continental shelf off the northwest of Scotland (in 1929, 1939 , $1959,1969,1971,1983-85$ and 1989), but none has exceeded 35.47 . It therefore seems

ganic guest-host complexes encompassing a number of apparently disparate structural types and some familiar compounds such as the heteropolys which had not been thought of in this way. We can now look forward to developments and applications.

\section{Department of Chemistry,}

PHILIP C. H. MitCHELL

The University,

Whiteknights,

Reading RG6 2AD, UK

that the salinity of the water entering the North Sea in January 1990 was perhaps the highest this century.

The late 1980 s were characterized by an increasing frequency of westerly weather patterns in the North Atlantic following a minimum in the 1970 s (ref. 4). It is possible that the high salinity of the water entering the North Sea in 1990 signals changes in current patterns in the Atlantic Ocean related to the changing weather conditions, bringing water from more southerly latitudes into the northeastern Atlantic. Abundance of plankton in the northern North Sea decreased during the

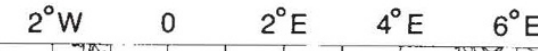
. 